\title{
Literatura e ensino: o imperialismo da imagem eurocêntrica
}

\author{
Luzia Aparecida Oliva dos Santos ${ }^{1}$, Antonio Aparecido Mantovani ${ }^{1}$ e \\ Genivaldo Rodrigues Sobrinho ${ }^{1}$
}

\begin{abstract}
This paper aims to propose some questions regarding the place literature has played in the school and the multiple ways that prevent the student to have an acceptable training as a reader within the standards required in social context. In the complex struggle involving literature and teaching, there is also the Indigenous and African culture as themes to be discussed in Basic Education as predict the regulating laws of these aspects. Keywords: Literature; Teaching, Indigenous culture; African culture.
\end{abstract}

Resumo: Este texto tem o objetivo de propor algumas questões relativas ao lugar que a Literatura tem ocupado no espaço escolar e as múltiplas vias que impedem o aluno de ter uma formação aceitável como leitor dentro dos padrões exigidos no contexto social. No complexo embate que envolve a Literatura e o ensino, destaca-se, também, a cultura indígena e africana como temas a serem debatidos na Educação Básica, conforme preveem as leis regulamentadoras desses aspectos.

Palavras-chave: Literatura; Ensino; Cultura indígena; cultura africana.

Introdução

Propõe-se aqui refletir algumas questões no entorno da temática da literatura, do ensino e da presença dos elementos culturais africanos e indígenas em textos que circulam no espaço escolar. Permear esses assuntos demanda um longo estudo, pois o Brasil, enquanto projeto formado pelo discurso eurocêntrico, ainda se arrasta pelo chão infantil quando lhe são cobradas as lições de cidadania que abarcam a africanidade e a indianidade. Por ora, é necessário ater-se apenas a alguns pontos para dar conta do pretendido.

Pensar a vaga que a literatura ocupa hoje no espaço escolar e, em seu escopo, a africanidade e a indianidade, é abrir um canal com a História da colonização para visualizar, ainda que turvamente, o discurso instituído que emoldurou o Brasil pelas lentes e imagens do poder europeu e como se processou a intersecção entre os povos africanos e indígenas.

Mais de quinhentos anos separam o país do início de sua História "mal contada" pelo discurso "oficial" com uma trama que ludibriou de escravos a senhores, por meio de

1 (UNEMAT/Sinop) 
artifícios autenticados pelas mãos de escritores, viajantes-cronistas, pseudodescobridores, escrivães semiletrados, entre tantos outros dizeres que estamparam a tessitura do que se convencionou chamar de nação brasileira.

Uma nação pigmentada por uma diversidade cultural singular não vista em outros continentes na mesma proporção. Nasce coberta pelos matizes indígenas que não se curvaram docilmente à exploração, e vai, gradativamente, se descolorindo ao escravizar a cordialidade do povo africano por meio da História que enrubesce a face dos que a observam com acuidade até os dias de hoje.

Não há como desvincular os fios da História da colonização brasileira do discurso tecido ao longo do tempo nos textos literários disponíveis nos livros didáticos apresentados como instrumentos de formação de leitores no contexto escolar. Poucas iniciativas se apresentaram como portadoras de uma visão mais alargada que pudesse levar em consideração uma nação de povos de idiomas diferentes e de cultura ágrafa. A oralidade indígena sequer foi observada, uma vez que a presença do poder português impunha a condição econômica antes da cultural e dominava, também, por ser uma cultura de posse da escrita. O negro, em condição de escravizado, não teve espaço para imprimir em terras brasileiras sua língua, sua literatura e demais bens culturais nos séculos em que o país se ocupava territorialmente e as riquezas luziam pelo ouro, pedras preciosas, açúcar e madeira. São essas trilhas que irão convergir para as reflexões aqui suscitadas, que não serão amplas em virtude do espaço e objetivos, mas necessárias ante os acontecimentos sociais, políticos, culturais e educacionais por que passa o Brasil nos últimos anos.

\section{A Literatura e ensino:}

O primeiro ponto considerado ao se pensar acerca dos rumos que tem tomado o ensino no Brasil, no que diz respeito à Literatura, é que não há uma receita pronta que forneça o devido sucesso na empreitada de formar leitores literários em tempos de tecnologias abundantes nas mãos dos alunos que frequentam o Ensino Fundamental e Médio. Se não há, deve existir um caminho que aponte alguma estratégia lúcida para os docentes que se embrenham em tal tarefa. Entenda-se Literatura no sentido amplo, a que circula em suportes virtuais, nos livros de crônicas e contos, romances, tanto os produzidos na contemporaneidade quanto os clássicos.

Discutir ensino de Literatura contraria uma série de pressupostos teóricos e críticos elaborados a partir de concepções que remontam a Aristóteles e Platão, e que se estendem aos dias de hoje, em torno de significados encerrados na fruição ou na utilidade da arte. Para Frye (2000, p.13), "todo corpo organizado pode ser aprendido progressivamente; a experiência mostra que há algo progressivo sobre o aprendizado da literatura". Assim posto, segundo o autor, é "impossível aprender literatura", pois o que se aprende é "crítica literária", uma vez que o corpo organizado chamado "arte" é que possibilita um estudo sistemático. Daí resulta outra questão: não se ensina literatura; ensina-se "crítica de literatura". Quando se trata, então, de transitar entre ensino e a presença de textos literários, há que se considerar que o educando necessita de uma formação progressiva de leitura para que alcance um patamar qualitativo dentro do que se espera de sua formação estética. A capacidade de fruição da arte consistirá no jogo de transgredir os limites da imaginação e da realidade.

Acrescente-se, ainda, outro elemento intrínseco: se o panorama não é dos mais promissores na leitura de textos literários da cultura local, regional ou nacional, 
imagina-se que não o é, também, quando se observa a presença dos textos da Literatura africana e de leituras que abordem a temática indígena. Nesse aspecto relevante dos estudos do pós-colonialismo, em que são trazidas a lume as vertentes culturais híbridas, nota-se uma resistência em se inserir no contexto educacional assuntos que permeiam a formação étnica brasileira. Raros os exemplos em que o espaço escolar subverte o imperialismo eurocêntrico da formação para discutir e desvendar os matizes que configuram a cultura brasileira. Entre os fatores que impedem essa construção mais transparente encontram-se o da formação docente em Letras e a dificuldade de organização de um corpus textual abrangente que concilie os objetivos de formação cidadã e literária concomitantemente.

Nesse novelo a ser desfeito em pontos, a seleção de textos apropriados ou relevantes para ocuparem o espaço escolar nem sempre é norteado pelas exigências especificas de formação progressiva. A leitura que o discente faz em casa praticamente inexiste, a não ser em raras famílias em que há consciência do valor que traz consigo na construção da cidadania. Nessas poucas famílias, o livro tem um espaço juntamente com o computador, o notebook ou o smartphone, nos quais o acesso ao texto, seja informativo ou literário, é possível. Noutras, o livro terá de ceder espaço ao arroz e feijão ou à fatura de água e luz. Os nós econômicos subtraem, na maioria das vezes, o suporte de leitura em casa, cabendo à escola o refúgio singular destinado à leitura de textos, entre eles o literário.

E a escola, com suas múltiplas funções atribuídas com o advento da pós-modernidade, também não consegue administrar tarefa tão laboriosa que é a de fazer o aluno, desde seus primeiros passos escolares, utilizar eficazmente a língua em diversas práticas sociais, sejam elas dentro e fora de seu espaço. No que diz respeito ao uso da língua portuguesa, pressupõe-se um rol de ações básicas ao aluno que vão desde um recado oral à leitura e interpretação de um poema, ou de um anúncio no outdoor, ou uma reportagem de revista.

O ser em formação depara-se com um universo de signos que vai além da letra e é provocado por um turbilhão de imagens fugazes, de traços, de cores, sustentados em suportes cada vez mais fáceis de adquiri-los. Em meio a esse mosaico, o profissional da Educação, em especial o formado em Letras, é desafiado a estabelecer linhas catalisadoras que permitam alinhavar o conhecimento estético inerente ao texto. Diante da facilidade de leitura proposta pela televisão, por exemplo, em que o cidadão não precisa se esforçar para construir o significado do que ouve e vê, o texto literário surge como um oceano a ser atravessado, quando o aluno é convocado a ler, compreender e produzir significados. Habituado a recebê-lo pronto, apresentará resistência na recepção de textos que requeiram um pensar além dos limites da visão, desentranhando do tecido textual o simbolismo recoberto pelos artifícios da arte.

Para que esse aluno seja direcionado com o mínimo de aproveitamento em sua formação como leitor, o formado para esse exercício é produto dos cursos de graduação, nos quais deveria aprimorar o conhecimento estético primeiramente, para, depois, lançarse ao desafio da atuação docente. Reside nessa instância um conjunto de fatores que vão inviabilizando gradativamente a excelência esperada na formação de leitores.

O primeiro envolve a formação de profissionais que atuam na Educação Básica, na fase inicial, em que se alfabetiza o aluno e se inicia o processo de leitura. Esses profissionais, geralmente, são pedagogos e não tiveram um contato específico com o texto literário ou estudos que o instrumentalizassem para o trabalho com o texto artístico em fases iniciais. Quando há, configura-se por meio de disciplinas como Literatura Infanto-Juvenil, de carga horária limitada, que não contribui de maneira eficaz para o profissional alcançar um patamar positivo no que compete à formação do leitor literário. 
Ainda que pese o fator assinalado acima, há que se apontar outro aspecto ligado à inquietação oriunda da experiência que se tem com o trânsito entre a teoria discutida na graduação e a prática docente: por que os alunos perdem o fascínio pela leitura de textos literários a partir do quinto ano? Nota-se que, nas fases anteriores, há uma dileção pelo livro e pela fantasia das histórias. Credita-se a isso, obviamente, a fase de desenvolvimento em que se encontram, mas a motivação não deveria perdurar nas fases subsequentes? Que fatores contribuem para que a formação do leitor literário se disperse entre outras tarefas mecânicas do estudo da língua?

O que se mostra como inquietação e como lacuna também se soma ao fator que aponta para a moldura das matrizes dos cursos de Letras, nas quais há um sem número de desenhos na distribuição das disciplinas. A área de Literatura nem sempre é compreendida como parte integrante e natural dos estudos de linguagem. Muitas vezes é tratada como um estudo à parte, ou seja, isolado, destacando a Linguística e a Língua Estrangeira como eixos mais importantes.

Percebida a presença significativa de disciplinas voltadas à teoria, à crítica e à leitura de textos literários propriamente, ainda remete a paradigmas antigos, pautados em fases ou movimentos, escolas literárias separadas diacronicamente, apontando para a brasileira e portuguesa apenas. Esse modelo é a estampa nítida do que se importou da educação eurocêntrica, uma vez que a Literatura em Língua Portuguesa também deveria abarcar a africana. Mudanças nesse sentido foram iniciadas somente em instituições que possuem uma capacidade mais ampla de ofertar cursos de licenciatura em Letras com literaturas de diferentes culturas, como em algumas das mais renomadas universidades brasileiras, a exemplo da USP, desde a década de 70 do século passado.

Sentido o engessamento que há no modelo um tanto corroído, é que se percebe a urgência em dar mobilidade nesses estudos para que a Literatura transite de forma sincrônica entre o corpo da matriz curricular para que o aprendizado não se dê de maneira fragmentada. No movimento estabelecido a estudos mais amplos, é possível, por exemplo, criar situações de leitura em que literaturas de uma mesma língua se encontrem ligadas por um elo temático, seja ele de cunho ideológico, de formação do sistema de um país em comparação a outro, de projeto nacional político ou literário, dentre outros.

Nessa perspectiva, a experiência ao longo dos anos de atuação do curso de Letras, da UNEMAT, campus de Sinop - MT, mostra que a maioria dos currículos atuais não dá conta de formar um discente com uma visão de intertexto, se ele estuda a Literatura em partes estanques, distribuídas nos semestres/anos aos quais se dedica no Ensino Superior, sem a percepção de que há relações inter/multi e transculturais no conjunto de obras disponíveis no corpus de cada cultura. O estudo poderá ser dosado sim, respeitando-se a gradação de conhecimento a ser construído, mas não fragmentado em parcelas que excluem questões importantes do debate como a cultura indígena e a africana. Especialmente no Brasil, em que há uma estampa multicultural impressa, também, na Literatura, não há como desconsiderar esses elementos dos estudos pertinentes aos cursos de graduação.

As observações desses fatores contribuíram para que se propusesse uma matriz na qual se garantissem disciplinas de Literatura fundadas em autores do Brasil, África, Portugal e autores locais, para estimular a leitura de obras em Língua Portuguesa. Os estudos, a partir desse formato, passam a considerar que o graduando em Letras necessita de estabelecer as conexões possíveis entre autores e obras, de diferentes culturas, que se abrigam sob uma curvatura maior, a literatura. Dessa maneira, obras africanas, por exemplo, são estudadas concomitantemente com as portuguesas e brasileiras, sem que lhes pese o epíteto do fragmento, estudadas à parte, como se não tivessem em seu escopo as mesmas 
condições estéticas, históricas, ideológicas e de estilo.

Ao lado da preocupação em entrelaçar obras de diferentes contextos, há, também, a questão legal, expressa na Lei Federal 11.645/08, que obriga o ensino de História da África, cultura afrobrasileira e indígena. Com a africanidade, o caminho torna-se um pouco mais aberto, em virtude da produção literária existente, que ainda merece atenção especial, e dos movimentos travados em torno de denúncias e proposições que tornaram a História desse povo mais visível. Com a causa indígena, há entraves muito mais agudos, quando se observa que não existe uma produção literária circulante no ensino, pois há um número restrito de escritores oriundos de culturas indígenas especificamente. $\mathrm{O}$ que há, no corpus literário brasileiro, por exemplo, são obras escritas pela alteridade que tratam da figuração do indígena. Sua História também é marcada por traços diferenciados, uma vez que, desde a "descoberta", implantou-se um discurso em torno de sua cultura que a desestabilizou enquanto ser nacional pertencente a mesma esfera de europeus e negros que somaram na formação étnica brasileira. Segundo Santos (2009, p.16-7), "o emaranhado de dizeres tornou-se fundamental para a construção da imagem da nação que se desnudava: o território foi olhado, descrito e cobiçado pela incontestável colonização".

Se o indígena foi apresentado por inúmeros textos como um homem desprovido de qualquer elemento que o nivelasse ao invasor, sua História foi-se autenticando por meio do mesmo discurso, alcançando na atualidade uma proporção desmedida no que tange à violência contra sua cultura, à invasão de suas terras e ao descrédito que lhe é imputado com os mesmos sentidos emersos de textos como os de Padre Anchieta e Padre Vieira. Se na gênese brasileira, a figuração do nativo se deu pelo motivo de os europeus não terem as noções de cultura que a contemporaneidade possui, a atualidade mostra claramente, seja pela mídia ou pelas ações culturais e do Estado, que a cultura indígena continua sob o estigma do ser diferente, o homem que não trabalha e que não se enquadra nos padrões do ser nacional. Os conflitos da terra estampados na mídia nos últimos tempos derivam justamente do tratamento destinado aos povos primitivos desde o primeiro contato que impregnou uma imagem distorcida no imaginário coletivo. Ultimamente, tem sido visto como uma ameaça aos fazendeiros, pois busca recuperar suas terras perdidas, uma vez que, isolados da sociedade em reservas muitas vezes improdutivas e distantes das cidades, para não incomodar o colonizador, agora não consegue sobreviver diante da escassez de recursos tão necessários na vida moderna da qual também faz parte. E o que dizer da presença dessa cultura no ensino?

Não há resposta à questão. Não há lugar para a cultura indígena nas escolas, senão em parcos textos canônicos que tematizam o indígena do ponto de vista do não-índio ou em raras ocasiões de datas comemorativas. $\mathrm{O}$ discurso que matizou a imagem do índio no Brasil teceu em sua rede nós muito fortes e difíceis de serem desatados em tempos de capital acirrado em torno das terras para o cultivo de grãos. A visão que se tem no Século XXI é de uma cultura mutilada pelas diferentes facetas do poder que se impôs desde o início da colonização e que se faz permanente. Uma das tentativas de amenizar a questão polêmica e urgente foi a criação de leis que deveriam contribuir para que as instituições de ensino observassem com mais acuidade o trabalho com o multiculturalismo.

\section{Literatura e leis}

A Lei 10639, sancionada pelo Presidente da República em 9 de janeiro de 2003, e revista em 10 de março de 2008 através de Lei Ordinária 11.645 que alteram a LDB (Lei de Diretrizes e Bases de 20 de dezembro de 1996, instituem a obrigatoriedade tanto no Ensino 


\section{Conexão Letras}

Fundamental quanto Médio da rede pública e privada, o ensino de História e Cultura indígena e afrodescendente, abrindo caminho para o trabalho de divulgação e valorização dessas culturas ao mesmo tempo presentes no cotidiano da comunidade quanto ignorada por ela.

Este novo olhar sobre a história e cultura indígenas, africanas e afrobrasileiras busca autoestimar indígenas e afrodescendentes, cuja cultura tem sido relegada, uma vez que impera no cotidiano escolar uma educação eurocêntrica, a começar pelo ensino da literatura que busca suas origens e laços na Europa desconhecendo o diálogo com as literaturas africanas de língua portuguesa. Ainda que a Lei seja uma realidade, faz-se necessário agir para que não caia no esquecimento, estabelecendo a necessidade de uma mudança a partir dos livros didáticos que devem estar em consonância com a Lei, contemplando temas voltados a outras culturas com ênfase ao que envolve a herança indígena e africana, cujos matizes são quase ignorados na cultura escolar nos dos próprios currículos que, conscientemente ou não, impõem uma vertente predominantemente eurocêntrica.

A África, para muitos, resume-se apenas nos navios negreiros, na seca e fome, na origem da AIDS ou nos animais soltos nas savanas. E o estudo sobre o negro no Brasil baseia-se, muitas vezes, nas grandes navegações com origem na economia canavieira, de onde advém o trabalho escravo que termina com a abolição da escravatura sem que estudos posteriores observassem a mão de obra pós-abolição. O Continente Africano continua pouco conhecido mesmo depois de a última Copa do Mundo, que teve como sede a África do Sul, país ainda considerado continente.

Em se tratando do indígena, este é lembrado constantemente pela Carta de Achamento, pela escola romântica e, idealizado ou não, em grande parte aparece a serviço do branco, perdendo a identidade e desconhecendo sua própria história, por considerar o início da História do Brasil com o "descobrimento" em 1500.

Se a função da escola é oferecer a cidadania, a formação de um sujeito crítico e consciente, o resgate da História e da Cultura dos que ficaram à margem dos estudos sobre a formação do povo brasileiro é um importante passo neste sentido. Inserir no cotidiano escolar o trabalho com a História e a Cultura indígena, africana e afrodescendente é imprescindível para a valorização desses povos e pode auxiliar na desconstrução de imagens estereotipadas das culturas.

A Literatura tem o poder de se contrapor ao discurso da elite branca, conservadora e responsável pelo apagamento da importância que o índio e o negro têm no desenvolvimento e formação da nação brasileira. Os estudos literários, com suas formas de representação agem inversamente a este apagamento, pois intencionalmente ou não, o estudo da literatura brasileira tem sido um importante meio de valorizar a cultura indígena, africana e afrodescendente em obras e autores como Castro Alves em Navio Negreiro, o mestiço em Lima Barreto e a voz subalternizada em Jubiabá, de Jorge Amado. Por sua vez, o indígena obtém relevância nas obras literárias de José de Alencar, Gonçalves Dias, Mário de Andrade e Darcy Ribeiro, dentre outros. Além dos textos literários, escritos pela visão do não-índio, inexistem textos direcionados para o debate na Educação Básica.

A escolha de textos representativos de autores pertencentes aos cinco países africanos de Língua Oficial Portuguesa pode ser um caminho para a inserção da História e da cultura destes povos. A inclusão de obras de autores de Angola, Cabo Verde, Guiné-Bissau, Moçambique e São Tomé e Príncipe contribuirá de forma significativa para clarificar como se deu parte da formação da identidade do brasileiro. Escritores como Mia Couto, Luandino Vieira, Pepetela, Ondjaki, Paulina Chiziane, Conceição Lima e Germano Almeida entre outros têm suas obras reconhecidas esteticamente por todos que estudam as literaturas de Língua Portuguesa. 
A aquisição das obras dos quatro primeiros autores citados acima pode ser feita sem maiores dificuldades principalmente as publicadas no Brasil. No entanto, as obras de autores africanos não publicadas em território brasileiro custam um preço considerado alto, além da dificuldade em adquiri-las pela falta de livrarias especializadas, falta de interesse de editoras sob alegação de que eles possuem um número reduzido de leitores.

Como se disse anteriormente, os estudos dessas obras congregam valores sócioculturais de povos falantes de Língua Portuguesa, estudados, a princípio, em pouquíssimos centros de pesquisa como na USP, UFRJ, UFMG e UFRGS. Hoje, esses estudos chegaram a universidades do interior. Isso tem permitido a formação e qualificação de um número crescente de professores que estão enriquecendo seus trabalhos na abordagem dessas culturas por vezes deixadas à margem. Além disso, os trabalhos de pesquisa em todos os níveis universitários têm se multiplicado após a publicação da Lei, o que contribuiu para abrir portas para o fomento de recursos para a realização de eventos acadêmico-científicos em todo país.

O trabalho que envolve elementos culturais africanos, afrodescendentes e indígenas deve ser implantado nas séries iniciais e um dos desafios é a formação do professor, conforme afirmado. Jorge e Amâncio (2008, p. 108) lembram que é preciso "formar professores (as) sensíveis à questão racial e propiciar aos professores (as) oportunidades de desenvolver em suas escolas trabalhos interdisciplinares com professores (as) de Geografia e História, principalmente". Num espaço escolar branco e excludente, a contemplação dos estudos voltados aos indígenas e africanos deve ser pautada a mostrar a riqueza e contribuição que os negros e ameríndios deram à formação do país e à cultura do brasileiro. Essa riqueza cultural presente no cotidiano do brasileiro deve ser apresentada como algo enriquecedor e não como simples produtos artesanais, danças e costumes exóticos aos olhos de quem não os compreende.

A Lei 10639/03 é uma realidade, um currículo prescrito, oficial e que permite adaptações, "traz consigo um caráter impositivo das políticas curriculares" (Santos, 2010, p. 47). Ressalta-se, no entanto, que não é resultado de um debate prévio junto à comunidade escolar. Esta recebeu a Lei, mas não estava preparada para pô-la em prática pela falta de especialistas em seu quadro, pela falta de materiais à disposição e mesmo pela irrelevância para alguns educadores, o que colocou o risco de a Lei se diluir num vazio, até porque parcela significativa da sociedade brasileira ainda ignora o preconceito racial a ponto de não sentir a necessidade de se criar uma lei, ou até afirma que as cotas nas universidades públicas já resolveram isso.

\section{Considerações finais}

Ainda que se quisesse apontar os caminhos mais viáveis para afinar o tratamento dado às culturas indígena e africana no Brasil, no que concerne ao ensino, não haverá êxito se o debate não for aprofundado e estendido à comunidade em todos os sentidos. Primeiramente, que as Universidades assumam o diálogo entre a formação e a atuação docente posterior. A partir da prática educativa que não exclui as minorias, poder-se-á ampliar a visibilidade em torno do valor cultural que os indígenas e africanos representam na constituição do povo brasileiro. Não serão as leis que irão reger a conduta por meio de imposições, pois o que se presenciou após sua instalação foi o descaso e a continuidade do pensamento escravocrata, da segregação e do preconceito. A prática constante e consciente é que dará direção ao olhar menos tenso em relação às culturas que conjugam as várias faces do brasileiro, permitindo que a gerações futuras amenizem os conflitos e demonstrem maior tolerância e respeito. 


\section{Conexão Letras}

Repensar o lugar do índio e do negro na Cultura, na História e na Literatura é recolher as marcas profundas instaladas nas raízes brasileiras desde sua fundação. Colocálos em evidência nos currículos escolares e desmistificar, ainda que gradativamente, o discurso eurocêntrico, formatado a partir do capital e da exploração, é avançar um degrau nas discussões que imprimem novas imagens acerca das culturas. Não se trata apenas de dar visibilidade a quem ficou ofuscado durante séculos. É, antes de tudo, uma maneira de desenvolver senso de identidade na diferença, o que caracteriza, de modo especial, a cultura brasileira sob o estatuto local e não mais aportado no eurocentrismo absoluto.

\section{Referências}

AMÂNCIO, Iris Maria da Costa; GOMES, Nilma Lino; JORGE, Míriam Lúcia dos Santos. Literaturas africanas e afro-brasileira na prática pedagógica. Belo Horizonte: Autêntica, 2008.

FRYE, Northrop. Fábulas de identidade: ensaios sobre mitopoética. Trad. de Sandra Vascocelos. São Paulo: Nova Alexandria, 2000.

SANTOS, Luzia Aparecida Oliva dos. O percurso da indianidade na literatura brasileira: matizes da figuração. Ebook. São Paulo: Editora UNESP, 2009. Disponível em: http://books.scielo.org.

SANTOS, Rosimeire dos. A lei $\mathrm{n}^{\circ}$. 10639/03: entre práticas e políticas curriculares. In:

História \& Ensino - Londrina, v. 16, nº. 1, p. 41-59, 2010. Disponível em: http://www. uel.br/revistas/uel/index.php/histensino/article/view/11598

Lei n. ${ }^{\circ} 11.645$, de 10 de março de 2008. Estabelece as diretrizes e bases da educação nacional, para incluir no currículo oficial da rede de ensino a obrigatoriedade da temática História e Cultura Afro-Brasileira e Indígena. República Federativa do Brasil. Brasília, DF. 